\title{
A Sociological Study of the Factors Affecting the Rural Development in District Gujranwala
}

\author{
Muqqadas Tanveer Cheema \\ Department of Sociology and Criminology, University of Sargodha
}

\begin{abstract}
Rural development usually refers to the procedure of improving the quality of life and financial well-being of group living in relatively areas. More than $69 \%$ of population of Pakistan is living in rural areas. They contribute in the economy of Pakistan, It accounts for $29 \%$ of G.D.P. Socioeconomic development of Pakistan cannot be successful to neglect the rural people and the rural areas. Rural development is influenced by a multitude of factors such as natural resources, human resources, technology, institutions and organizations including co-operatives. The study was define the socio economic characteristics of respondents, to explore the perception of people towards the rural development. The study was find out the level of knowledge about the factors affecting the rural development. Tehsil was chosen all the way through simple random sampling. Two villages was selected by simple random sampling. 120 respondents was chosen through simple random sampling methods from selected tehsil of district Faisalabad. To custody understanding objectives a well-organized questionaire was used for data collection. The collected data was analyzed by using proper statistical methods. The results was presented in the shape of SPSS.

DOI: $10.7176 / \mathrm{JCSD} / 63-02$
\end{abstract}

Publication date: January $31^{\text {st }} 2021$

\section{INTRODUCTION}

The word development does not mean a general process of social change. A process of development should have three major elements. Economic: The economic development of any society base on, which will manufacture the commodities and resources necessary for life. Social: The provision of a collection of social facilities and services (i.e., health facilities, educational facilities and welfare). These are non-productive needs of a society. Human: The improvement of the people themselves, both individually and communally, to understand their full potential, to utilize their skills and to play a positive part in shaping their society (Asim, 2009).

Rural development usually refers to the procedure of improving the quality of life and financial well-being of group living in relatively areas. Rural development has usually centered on the development of natural wealth such as agriculture and forestry. Though, changes in international production networks and greater urbanization have changed the nature of rural areas. Increasingly tourism, recreation and place manufacturers, have replace resource origin and agriculture as main economic drivers. Education, private enterprise, physical infrastructure (roads and rail network, transportation), and social infrastructure all play significant role in development of rural areas. It also characterizes by its significance on locally created economic development strategies. In compare to urban region, which have many similarities, rural areas are highly distinctive from one another. For this cause there are a large no of rural progress approaches used internationally (Zulfiqaret al., 1999).

Rural segment plays a vital role in the economy. The profession of farmer is not only to produce food for our local industries, but it earns valuable foreign exchange for the national development. All efforts to develop and improve the conditions of rural areas through different ways. Rural development is the natural course of events, to change the rural areas. Rural development is a process carried out by someone (including agencies in the public and private sectors), which have the goal of improving quality of life (income, employment in the service etc) in rural areas. In the second sense rural development is a set of quality of life goals to be achieved. Basically, rural development is a process through collective efforts to improve well-being and self-realization of the targeted people in the rural areas (Ashraf, 1992).

The economic development of any country is directly concern with the development of rural areas. As $67 \%$ of the population reside in the rural Pakistan, while share of the rural in agriculture sector to country GDP is $21 \%$. Rural development doesn't indicate only agricultural development, it calls for improving the financial and social environment of the rural people by raising their income and provided them with basic facilities like better housing, paved street, water supply, health services, sewerage, roads, education, and social relationship for participating in cultural and political activities. In the early days of global development assistance, development initiative was mainly driven by "top-to-bottom" or performance approach. Development projects were prepared by government line departments which often created wrong solutions. For the last twenty years there has been a stable add to in new community development actions mostly by (NGOs) and the voluntary persons and donor sectors. As a consequence, community development initiatives have been changed to what is currently known as the "bottom up" or participatory approach base on the law that people living in a community are the greatest source of information and the best source to manage their desires (Muhammad and Nafees, 2009). 
After 1989, the significance of research about rural progress has grown due to the information that for the modernization of a rural community it's a compulsory situation that of having an accepted local development policy for accessing development finances. In the North-East region of Romania the significance of rural-urban influences should be explore when a rural development strategy is self-possessed due to the importance of agricultural productivity based incomes in every one branches of the national economy (Codrin, 2011).

Contemporary actions around the world have shown rising concerns for the $76 \%$ or more people live in the rural areas. This is reasonable by the high association that exists among rural living and poverty with this location particularly exacerbated in African state. Poverty can be determined by a number of dynamics including the level of financial growth, the pattern of government spending the way expansion affects the poor, and the primary distribution of income. Agriculture employs almost one-half of the labor force dependent on agriculture productivity in Africa and other developing countries. Rural communities and specially the rural poor are directly or indirectly dependent on farming, food processing, forestry, fishing, and trade (Nchuchuwe and Friday, 2012).

\subsection{Crisis in Agriculture}

Pakistan is still predominantly an agricultural country even after half a century of concerted efforts towards industrialization. The dominant production activity of the rural sector is agriculture. Although migration from rural to urban areas has increased considerably over the past two decades, nearly three-fourths of the population still makes its living through farming and lives in villages. This makes agriculture the largest employer in the economy, accounting for 54 percent of the country's total labor force and supporting, directly or indirectly, 70 percent of its population. There is no denying the fact that agriculture has an important role to play in overall economic growth, poverty reduction, resource management and over all development. It has direct bearing on the economic growth by having $1 / 5$ share directly in the economy and further indirectly through adjustments and expenditure patterns of rural communities. As reported in a study undertaken by World Bank (1994) each one-percent increases in percapita agricultural growth leads to 1.5 percent increase in per capita in non agricultural growth. Increasing incomes in agriculture are spent on locally produced goods and services and help to increase rural employment, reduce poverty and serve as a pre-condition in enhancing rural development. Moreover, the contribution of agriculture to manufacturing is substantial. Industries dependent on agriculture have the highest value added and indirectly exert significant influence on overall growth of the economy. This dependence of the economy on agriculture has created a crisis situation; Pakistan has been facing for some years now. The steady growth rate of the yester years is a dream and uncertainty now surrounds its performance. The growth rate of agriculture touched as low as 0.12 percent during 1990s. This has happened in a country where the rate of agricultural growth, on an average stayed around 6.77 percent in the 1960s and about 6.14 percent in the 1980s. Non-diversification of the rural economy, an over pressurized agriculture (particularly the crop production), intensive cultivation of land without conservation of soil fertility and soil structure have led to decline in production and productivity with the attendant uncertainty. Excessive dependence on agriculture has created a culture of excessive and indiscriminate use of fertilizers, pesticides, fungicides and herbicides combined with unscientific tapping of underground water that has made the agricultural economy vulnerable to all sorts of fluctuations. The growth rate of agriculture started declining during the 1990s. It was 0.12 percent in 1996-97, picked up again and stayed just at 0.35 percent during 1998-99, even in the wake of ongoing agricultural and rural development efforts. Policies to get short term gains have only succeeded in putting at stake the long term objectives such as self-sufficiency in food etc(Zulfiqaret al., 1999).

\subsection{Demographic Characteristics of Households}

Aside from economic and social indicators, we make use of significant demographic indicators to characterize poverty and household living standards. The demographic characteristics of the household can be broadly classified into three categories, as follows:

\subsubsection{Household Size and Structure}

This indicator is an important one as it shows a possible correlation between the level of poverty and household composition. Household composition, in terms of the size of the household and characteristics of its members (such as age), is often quite different for poor and nonporous households. The Pakistan Integrated Household Surveyor 1998/99 shows that the poor tend to live in larger households with an average family size of 8.4 persons in the poorest quintile compared with 6.2 in the nonporous quintile. Similar patterns are found in most developing and low-income countries. Generally it is recognized that more healthy, educated, and adult members in a household contribute to their income levels and reduce poverty; if household members are not adult and educated, they can become the cause of poverty. It is hypothesized that the larger the household size, the higher the level of poverty incidence, and vice versa.

1.2.2. Dependency Ratio

For a given household size, a larger number of children and elderly members would imply a smaller number of earners in the household. In the present analysis, the dependency ratio is calculated as the ratio of the number of 
members below 15 and over 64 to other household members. Furthermore, child and older member dependency ratios are also calculated using the same formula. This ratio allows us to measure the burden on members of the labor force within the household. One might expect that a high dependency ratio would be correlated positively with the level of rural household poverty.

\subsubsection{Female-Male Ratio}

The female-male ratio or sex ratio is important in a household in determining the attitude toward work. Although not to be assumed a generalization, female household members in rural Pakistan are often constrained by cultural norms from working outside their household. This suggests that a high female-male ratio might be related to household poverty.

\subsubsection{Age and Gender of Household Head}

The age and gender of the household head are also important in determining the attitude toward employment. It is widely believed that the age and gender of the household head significantly influences rural poverty. The age of the household head has a similar role to sex composition, as discussed above.

Pakistan is still predominantly an agricultural country even after half a century of concerted efforts towards industrialization. The dominant production activity of the rural sector is agriculture. Although migration from rural to urban areas has increased considerably over the past two decades, nearly three-fourths of the population still makes its living through farming and lives in villages. This makes agriculture the largest employer in the economy, accounting for 54 percent of the country's total labor force and supporting, directly or indirectly, 70 percent of its population. There is no denying the fact that agriculture has an important role to play in overall economic growth, poverty reduction, resource management and over all development. It has direct bearing on the economic growth by having $1 / 5$ share directly in the economy and further indirectly through adjustments and expenditure patterns of rural communities. As reported in a study undertaken by World Bank (1994) each one-percent increases in percapita agricultural growth leads to 1.5 percent increase in per capita in non agricultural growth. Increasing incomes in agriculture are spent on locally produced goods and services and help to increase rural employment, reduce poverty and serve as a pre-condition in enhancing rural development. Moreover, the contribution of agriculture to manufacturing is substantial. Industries dependent on agriculture have the highest value added and indirectly exert significant influence on overall growth of the economy. This dependence of the economy on agriculture has created a crisis situation; Pakistan has been facing for some years now. The steady growth rate of the yester years is a dream and uncertainty now surrounds its performance. The growth rate of Gill, Mustafa, and Jehangir 1180 agriculture touched as low as 0.12 percent during 1990s. This has happened in a country where the rate of agricultural growth, on an average stayed around 6.77 percent in the 1960 s and about 6.14 percent in the 1980s, Pakistan. Non-diversification of the rural economy, an over pressurized agriculture (particularly the crop production), intensive cultivation of land without conservation of soil fertility and soil structure have led to decline in production and productivity with the attendant uncertainty. Excessive dependence on agriculture has created a culture of excessive and indiscriminate use of fertilizers, pesticides, fungicides and herbicides combined with unscientific tapping of underground water that has made the agricultural economy vulnerable to all sorts of fluctuations. The growth rate of agriculture started declining during the 1990s. It was 0.12 percent in 1996-97, picked up again and stayed just at 0.35 percent during 1998-99, even in the wake of ongoing agricultural and rural development efforts. Policies to get short term gains have only succeeded in putting at stake the long term objectives such as self-sufficiency in food (Zulfiqaret al., 1999).

\subsection{Objectives:}

1) To study the socio economic characteristics of respondents

2) To explore the perception of people towards the rural development.

3) To identify different development activities in the areas by government and NGOs.

4) To find out the level of knowledge about the factors affecting the rural development.

5) To suggest some policy measures on the issue.

\section{REVIEW OF LITERATURE}

Chishti and Lodhi (1988) reported school attendance decision using data from socioeconomic survey of Karachi conducted during 1987-88. Their analysis reveals that the decision to attend school depends on the gender of the potential student, household income, parents' education, and the ethnic background. Karachi is the largest metropolitan city of Pakistan with the highest literacy rate in the country. Hence findings for this city cannot be automatically generalized for the rest of the country, especially rural areas.

Asian Productivity Organization (2004) examined that in the expansion of rural areas in Asia and Pacific, the synchronization of a range of rural development actions has been essential to maximize and supporting rural development. This has been skillful in a main way with the adoption of an Integrated Rural Development (IRD) approaches in various states. The IRD programs generally require the establishment of essential coordinating institute at the public stage. The experience in the performance of such programs expose new central organization 
would purely create an additional section of bureaucracy and has not been useful in coordinating the different actions done by different sectors in the rural development efforts. Some IRD programs (Sri Lanka, Nepal and Malaysia) have set up coordinating method at the lower levels involving project offices and local government units. With the decentralized manner of project implementation, people's participation in the practice of rural development has been worried and made to central component of the program.

Talatet al. (2004) studied although reducing rural poverty has been the key agenda of economic reforms in Pakistan; the rural poverty continues to rise during the 1990s. The causes of rural poverty are complex and multidimensional. The rural poor are quite diverse both in the problems they face and the possible solutions to these problems. The rural poor are not homogeneous in terms of their natural or economic environments or their sources of income. To examine the causes of rural poverty and what accounts for its persistence and what policy measures should be taken to alleviate it. Poverty estimates using official poverty line suggest the high prevalence of rural poverty ranging from $39 \%$ to $48 \%$ in all provinces. Rural poverty is found to be strongly correlated with lack of asset in rural areas. The unequal land ownership in the country is found to bone of the major causes of poverty as poverty level was the highest among the landless households followed by non-agriculture households. The landless households are substantially high in rural areas. About $75 \%$ households own no land in the country. Notably $0.05 \%$ households own greater than 2 hectares of land in Punjab as well as in Sindh suggesting a highly skewed land ownership pattern. Punjab has the highly unequal land ownership pattern followed by NWFP, Sindh and Baluchistan. The highly unequal land distribution seems to have resulted in tenancy arrangements such as sharecropping resulting in high prevalence of absolute poverty particularly in Sindh. A broad-based land reform program including land redistribution and fair and enforceable tenancy contracts together with rural public works programs and access to credit - is critical for reducing rural poverty in Pakistan.

Shabbirat al. (2005) to identify the factors affecting the parents' attitude towards the skill development and job opportunities for their daughters. The results show that parents were in favor of males' technical education because males extend more support to the parents than females and males have more opportunities for job than females. Furthermore, daughters do not work due to family traditions and male members do not allow daughter for paid job because of briary pressure. Bad environment at the work place was also one of the important factors affecting skill development and job opportunities for females.

Imran et al. (2006) examined a number of associated ideas and problem of rural development by looking at agriculture and economy of rural people, features of rural areas, spatial size and tendency of rural development. Pakistan is basically an agricultural country. In Pakistan agriculture is the main profession of rural people and rural areas are the main reservoir of poverty and their livelihood depend on farming. Poverty level is much higher in rural areas than urban areas of Pakistan. An experimental investigation of the overall determinants of rural development is based on unemployment, Inflation and growth rates have the important effects to rural poverty in Pakistan. Rural poverty elimination is impossible unless the economy generates opportunities, job creation entrepreneurship and sustainable livelihood.

Atmiset al. (2007) analyzed women participation in forestry. They find out the significant indicators that have an effect on the contribution of women were women in relation to the perception (1) the dependence of forests, (2) the excellence of the cooperative, (3) the worth of the organization of forests, and (4) the quality of forests. These factors explain $59 \%$ of the women contribution. Results indicated that marital status, age, wealth and growth of population and are most significant variables of variation in levels of contribution.

Abdul and Ahmed (2007) investigated that poverty is rampant in the rural areas of Pakistan, where people are in a state of deprivation with regard to incomes, clothing, housing, healthcare, education, sanitary facilities and human rights. Agriculture generates nearly 20.9 percent of the country's GDP and provides employment for 43.4 percent of its workforce. Most importantly, 65.9 percent of the population living in rural areas is directly or indirectly dependent on agriculture for their livelihood. Rising population, shrinking agricultural land, increasing demand for water resources, widespread land degradation and inadequate infrastructure appear to be major concerns of the agriculture sector in Pakistan. An attempt has been made to examine the population growthagriculture growth-poverty alleviation linkage. It is argued that agriculture will continue to be one of the most important sectors of Pakistan's economy for years to come. To alleviate poverty, it is suggested that Pakistan enhance the productivity of the agriculture sector through the provision of a series of inputs including provision of easy credit to the small farmer, availability of quality fertilizers and pesticides, tractor and harvester services, improvement in the effectiveness of the vast irrigation system and, finally, farmer education. It is concluded that the high rate of population growth needs to be curbed for increased agricultural productivity to have any significant effect on poverty in rural areas of Pakistan.

Muhammad and Faheem (2007) studied has been carried out to measure the incidence of government spending on health in Pakistan at provincial, both rural and urban level; using the primary data of the Pakistan Social Standard Living Measures Survey (PSLM), 2004-05, and by employing the three-step Benefit Incidence Approach (BIA) methodology. The paper reviews the national policies emphasizing health services as well as the trend in access to and public sector spending on health care facilities in Pakistan. The study explores the 
inequalities in resource distribution and service provision against the government health expenditures. The rural areas of Pakistan are the more disadvantaged in the provision of the health care facilities. The expenditures in health sectors are overall regressive in rural Pakistan as well as at provincial and regional levels. Mother and Child subhead is regressive in Punjab and General Hospitals and Clinics are regressive in all provinces. Only the Preventive Measures and health facilities sub-sector is progressive in Pakistan. Public health expenditures are prorich in Pakistan.

Muhammad etal. (2008) studied the role of Sarhad Rural Support Program (SRSP) in gender development in rural villages of District Peshawar. Results show that the SRSP had introduced a number of interventions to mobilize women. Woman Community Organizations (WCOs) were established which were reported as the most primary source of motivation. Because of patriarchal nature of society; males, social workers, religious leaders and teachers were contacted to pave way for the formation of the WCOs. This enabled SRSP to form WCOs and contact the females. To accelerate social mobilization, the women community was sensitized through social organizers and interventions were designed and implemented that were based on societal needs. All these efforts mobilized the women to an extent where they started making decisions independently. In spite of concerted efforts of SRSP to mobilize women for socioeconomic development, a lot of work is still needed to make WCOs an independent and functional institution.

Ejaz A and Karamat (2008) reported the twin problems of low school enrolment and high gender disparity have widely been addressed in the literature. To investigate the determinants of schooling of children overall and separately for boys and girls using primary data of rural households. The empirical estimates based on the model point to certain findings. The first enrolment of children in schools is delayed and it is more severe for girls. There exists gender disparity in children's schooling. The head of the household education significantly increases the probability of overall children's schooling. It has a greater effect on boy's schooling and does not matter in girl's schooling. The head of household income has a slight impact on overall children's enrolment but for girls it is significantly higher than boys. Parental education also significantly increases the probability of child's schooling. Mother's education exerts a much stronger effect of increasing school enrolment. The estimates of the gender specific determinants suggest that maternal education increases the likelihood of girl's schooling enrolment than of boys. Higher per capita income of households and ownership of assets by households increases the probability of school attendance. Family size and household composition also plays a significant role. Children from large families are more likely to go to school but children from households with a large number of children (up to 15 years) are less likely to go to school. Similarly, children from households with larger number of children (in the age group of 5-15) are less likely to go to school. It is sibling size (in both age groups) which hinders the schooling of children, not the family size.

\section{MATERIAL AND METHODS}

\subsection{Introduction}

This chapter describes the methodological aspects of collection and analysis of information. The materials and methods provide a path to researcher how to complete the process of collection, analyzing and interpretation of data. The research design is the "blueprint" that enables the researcher to come up with the solutions to the problems encountered during the research (Nachmias and Nachmias, 1992). It gives the study design, selection criteria for respondents, sampling procedures, sample size, selection and different statistical techniques used for data analysis, such as Uni-variate analysis and Bi-variate analysis. Therefore, the main objective of this chapter is to explain various tools and techniques employed for the data collection, analysis and interpretation of the data. They are discussed at length in this chapter.

\subsection{Universe}

Universe is any set of individuals or objects having common observable characteristics constitute a population or universe. The study was conducted in rural areas of District Gujranwala.

\subsection{The Sample}

The sample is a smaller representation of a larger whole (Chaudhry, 1984). The factors of time cost and physical limitations usually play an important role in social researches. Therefore it is more economical and efficient to base studies on samples rather to study the entire universe. At the first stage tehsil Jhang were selected from District Jhang, at the second stage three union councils (Haidery UC-96. Gulabwala UC-94 and Gohar Shah UC-88) and two villages from UC-96 are MouzaPatwana and Pakywala, Villages of UC-94 are Shairwala and Qulkoraiyan and Villages of UC-88 are Shabirabad and BaloShahabalwere selected through simple random sampling technique. At the end a sample of 120 respondents were selected through convenient sampling technique and interviewed by using a well-designed interview schedule. Descriptive and inferential statistical technique were used for data analysis. 


\subsection{Development of Interview Schedules}

It was decided to construct an interview schedules i.e. the closed-ended and open-ended for the quantitative and qualitative analyses respectively. Interview schedule was constructed with the help of supervisor was examined by the educationists for any possible technical modification in it. Experts' viewpoint regarding the questionnaire ensures its content validity (Nachmias and Nachmias, 1992).

In order to design the questionnaire the two basic principles were kept in mind. First, questions were made by keeping the viewpoint of respondents so that chance of confusion eliminated. Second, during construction of questionnaire some biases were avoided such as jargon, slang, ambiguity, confusion, emotional language, prestige biases, double barreled questions, threatening questions, false premises and double negatives. These principles helped the researcher to motivate the respondents for maximum information (Foddy, 1993). Avoiding sensitive and awkward questions in questionnaire formulation led to win the trust of respondents during interview. In addition, formulating the questionnaire, the major aspects contents, structure, format and sequence were taken into account (Nachmias and Nachmias, 1992).

\subsubsection{Pretesting}

The pre-testing is a tryout of the interviewing schedule to see how it works and whatever changes are necessary before actual data collection. The pre-test provides means of catching and solving unforeseen problems in the administration of the interview schedule (Goode and Hatt, 1952).

Before collecting the actual data ten interviews were conducted in order to pre-test the validity of interviewing schedule. During pre-testing some mistakes were identified. To overcome those few modifications were made to enhance the validity of data.

\subsection{Analysis}

Quantitative data was analyzed through various statistical techniques as, univariate /descriptive and bivariate techniques. In univariate analysis such as frequency, percentage and measures of central tendency (mean, standard deviation) were used to describe the data. In bivariate analysis, relationship among different variables was examined through applying chi-square and gamma tests.

\subsubsection{Use of SPSS}

This revolutionary statistical analytical software system was called SPSS that stood for the Statistical Package for the Social Sciences. Nie, Hull and Bent (1968) developed SPSS out of the need to quickly analyze volumes of the social science data gathered through various methods of research techniques. The SPSS was used first time at Stanford University.

SPSS is the one of the most widely used software packages in the world of social sciences. It has been very crucial in facilitating the data of research using individuals as well as discrete units of analysis (Wellman, 1998). Further it is clear that SPSS technology has made difficult analytical targets easier by advances in usability and to data access and also enabling the researchers to benefit from the use of quantitative techniques in making decisions. It helps researcher to input the data on computer and can save time from the laborious and exhaustive work of an analysis.

\subsubsection{Univariate Analysis}

It is defined as methods for analyzing data on a single variable at a time. In univariate analysis, each variable in any data set is explored separately. It also looks at the range of the values but as well as the central tendency measures of the values. It describes the pattern and trend of response to the variable, also describes the variable on its own. Descriptive /univariate statistics interpret and summarize data and also it describes individual variables.

Frequency distribution of different variables (Nominal variables and Ordinal variables) is done by identifying the lowest and highest values of the variable and then putting all the values of the variable in order from lowest to highest. Further, count the number of appearance of every value of the variable. It is a count of the frequency distribution with which each value occurs in the set of data. Frequencies distributions can also be presented in the form of percentage distributions and cumulative percentages. Descriptive data can be presented through graphing, is a way of visually presenting of the data. Some researchers grasp the information into graphical form but it can be presented in a text format.

3.5.3. Bivariate Analysis

Bivariate analysis is applied to see the relationship/association between the two variables. It is explained in other words, the variation which is explained by one variable is pattern in such a manner that its variance is not randomly distributed in connection with the other variable. Bivariate analysis was used to find out association of socioeconomic characteristics of the farmers and their knowledge and adoption level of modern agricultural technology. In its general form, relationship simply refers to the degree to which it becomes easier to predict a value for the predict variable if one knows a case's value on the independent variable. This measure of association helps to understand relationship. Chi-square and gamma statistics were used to check the relationship/association between dependent and independent variables. 


\subsubsection{Chi-Square Test}

Chi-square test is denoted by symbol $\chi 2$. Chi-square is defined as, a statistical test used to compare the observed with frequencies with expected frequencies, it would expect to obtain according to a specific hypothesis also to determine the degrees of independence (Fisher, 1928). One of the most general and useful ways to observe information about the social globe is in the set-up of a table. There are many ways we might show information related to the question, but perhaps the most frequent and easiest to comprehend method is in a table. The formula for calculating chi-square $(\chi 2)$ is:

$\chi 2=($ fo-fe $) 2 / \mathrm{fe}$

Chi-square is the sum of the squared difference between observed (fo) and the expected (fe) frequency (data) (or the deviation, d) and divided by the expected frequencies in all possible categories. - capital sigma tells to compute the fractions for every cell and then sum over all cells to get $\chi^{2}$. The following steps are involved to compute the chi-square:

i- $\quad$ To find out the difference between each observed frequency and the correspondence expected frequency for each cell in the table

ii- $\quad$ Square for each difference.

iii- $\quad$ Divide each squared difference by the respective expected frequency.

iv- $\quad$ Add the resulting divisions.

There are certain assumptions of chi-square. At first, data is random sample of population, secondly data based on nominal/ ordinal, thirdly there is not any expected frequency less than 5 and at lastly there is not any empty cell in frequency.

\subsubsection{Gamma Statistics}

Gamma test is defined as, the strength of association/relationship of the cross tabulated data when two variables are being measured at the ordinal level of measurement (Sheskin, 2007). The values range from -1 means (100 percent negative association), or (perfect) to +1 means ( 100 percent positive association), or (perfect agreement), and value of zero shows the absence of association in the variables. This test is also known as Goodman and Kruskal's gamma test). It's very close to Somers'D and to Kendall's tau.

In descriptive statistics, Gamma test statistic is an index of association between two variables which measured on ordinal levels. Suppose, if two pairs of scores are examined, they must either be concordant, in the sense that the one ranked higher than the other on the first variable is also ranked higher than the other on the second variable, or discordant.

The value of a gamma test statistic, $(\Gamma)$ depends on two quantities:

$$
\text { Ns - Nd }
$$

Gamma $=$

$$
\mathrm{Ns}+\mathrm{Nd}
$$

Formula shows that the size and the direction of gamma whether its positive or negative, are functions of the relative number of same order as (Ns), versus inverse order (Nd) pairs. However, more Ns pairs make gamma positive and more $\mathrm{Nd}$ pairs make gamma negative and the larger the difference between $\mathrm{Ns}$ and $\mathrm{Nd}$, the larger the size of the coefficient (irrespective of sign).

- Ns, the number of pairs of cases ranked in the same order on both variables (number of concordant pairs), - $\quad \mathrm{Nd}$, the number of pairs of cases ranked differently on the variables (number of discordant pairs).

Gamma indicates the results in following way:

$$
\text { i- Gamma } \quad=\quad \text { Ns }-0 \quad=1.0
$$

$\mathrm{Ns}+0$

A gamma of 1.0 indicates that the relationship between the variables is positive, and the dependent variable can be predicted without any error based on the independent variable. When Ns is zero, gamma will be-1.0, indicating a perfect and a negative association between the variables

$$
\begin{array}{cc}
\text { ii-Gamma }= & 0-\mathrm{Nd}=-1.0 \\
0 & +\mathrm{Nd}
\end{array}
$$

When $\mathrm{Ns}=\mathrm{Nd}$, gamma will equal zero:

$$
\begin{array}{llll}
\mathrm{iii}-\mathrm{Gamma}= & \mathrm{Ns}-\mathrm{Nd} \\
\mathrm{Ns}+\mathrm{Nd} & \mathrm{Ns}+\mathrm{Nd}
\end{array}
$$

A gamma of zero reflects no association between the two variables; hence, there is noth $\neg$ ing to be gained by using the independent variable to predict order on the dependent variable.

\subsection{CONCEPTUALIZATION}

Conceptualization is the application of certain scientific terminologies with a view to clearly communicate the intended outcomes of the study. The need for the conceptualization and defining the general concepts with specific and purified component is important. Some of the concepts used in the present study are equipped as under: 


\subsubsection{Social Economic Characteristics}

According to Khal and Davis (1955) socio-economic characteristics means a complex of attitudes, that is interrelated but does not from a single dimension.

It refers to one's standing within the society in relation to others. It is complex concept different scholars have define it differently. In the present study the indicators of socio-economic status.

- Age

- $\quad$ Education

- $\quad$ Family type

- $\quad$ Size of land holding

- $\quad$ Tenancy status

- Income

3.6.1.1. Age

Age is one of the important variables in any social research. It refers to the number of completed years since birth of the respondent. It affects the attitude and behaviour of a person at different stages of life;

In the present study age of the respondents was categorized into:

$$
\begin{aligned}
& \text { Up to } 18 \\
& 19 \text { to } 36 \\
& 37 \text { to } 54
\end{aligned}
$$

\subsubsection{Education}

Above

According to Francis (1970) education is a consciously controlled I process whereby changes in behaviour are produced in the person and through the person within the group.

The education of mothers creates a deep impression on the atmosphere of the family. In the present study education has been recognized as the total number of years of schooling completed by the respondents in educational institution. Education of respondent was taken as one of the indicates of families, socio-economic factors. The educational categories were as follow:

i. Illiterate

ii. Primary-Middle

iii. Matric and above

Type of Family

The family is a group of intimate people emotionally, involved and related either by blood, marriage or adoption, responsible for the reproduction and rearing of children and living together (Chaudhry, 1988). There are two type of families which as discussed.

$$
\text { a. Nuclear family }
$$

b. Joint family

a. Nuclear Family

Ordinarily unclear type of family consists of a parent couple and their children. By nuclear family here the researcher meant husband, wife and their unmarried children living together.

\section{b. Joint Family}

The joint family consists of nucleus of blood relatives surrounded by a number of married persons and their children, which is also called as consanguine family.

In the present study joint family consisted of brothers, cousins, Grand mother and Grand father living in household with their spouses.

\section{Land Holdings}

In the present research landholding represented the piece of land either owned or rented in and cultivated by the respondent. The size of landholding was categorized as follows:
1. Up to 6
2. $\quad 7-12$
3. Above 12

Tenancy Status

It refers to the relationship of man to his landed property. Tenancy status is an important factor in establishing one's social position in rural areas.

Tenancy status is categorized as follows.
1. Owner
2. Owner-cum-Tenant
3. Tenant

3.6.1.3. Income

Income of the respondents defined as the enumeration received periodically for work or services performed" (Popenoc, 1977). 
In the present study income means the total gross earnings of the respondents from land, as well as from other subsidiary sources, if any. The monthly income of the respondents from all sources was categorized as follows:

i. Up to Rs. 15000

ii. Rs. 15001-30000

iii. Above Rs. 30000

Index Variable Construction

To study the combine effect of all the variables in predicting the response variable all the statements in matrix questions are combined together to form a single prime or main variables known as index variable. However, before the development of index variable, it is pre-requisite to ensure the element of consistency among all the items in the matrix question. For this purpose, a reliability check is carried out and the value of Cronbatch Alpha is determined.

The Statistical Package for Social Sciences (SPSS) used to find Cronbatch Alpha values. During the reliability check, if the value of Alpha remains in the range 0.7 to 1.0 , because all items or statements or matrix questions are highly correlated and representing one idea. This facilitates the study of combine effect that otherwise is not possible.

On confirmation of element of consistency, the score on all the items in a matrix question recorded through response categories is summed up. The minimum and maximum value is determined through sub-menu descriptive statistics followed by frequencies. The next step the maximum and the remainder is divided with the number of descried level or categories in index variable.

\section{RESULTS AND DISCUSSIONS:}

\section{Table \# 01}

Distribution of respondents according to their Age

\begin{tabular}{|l|c|c|}
\hline & Frequency & Percent \\
\hline Up to 18 & 14 & 11.7 \\
\hline 19 to 36 & 49 & 40.8 \\
\hline 37 to 54 & 52 & 43.3 \\
\hline Above & 5 & 4.2 \\
\hline Total & 120 & 100.0 \\
\hline
\end{tabular}

Table 1 --- showed that age of respondents, $43.3 \%$ respondent $37-54$ years age followed by $40.8 \%$ respondent 19 36 years age, $11.7 \%$ respondentsupto 18 years age and $4.2 \%$ respondents have above.

\section{Table \# 02}

Gender of the respondents

\begin{tabular}{|l|c|c|}
\hline & Frequency & Percent \\
\hline Male & 120 & 100.0 \\
\hline
\end{tabular}

Table 2 --- showed that age of respondents, $100 \%$ respondent of male.

Table \# 03

Nature of job of respondents

\begin{tabular}{|l|c|c|}
\hline & Frequency & Percent \\
\hline Govt. Servant & 11 & 9.2 \\
\hline Private Job & 2 & 1.7 \\
\hline Farmer & 74 & 61.7 \\
\hline Business & 5 & 4.2 \\
\hline Labor & 7 & 5.8 \\
\hline Student & 21 & 17.5 \\
\hline Total & 120 & 100.0 \\
\hline
\end{tabular}

Table 3 --- indicated that nature of job of respondents, $61.7 \%$ respondent farmer followed by $17.5 \%$ respondent students, 9.2\% respondents Govt. servant, 5.8\% respondent labor, $4.2 \%$ respondent business man and $1.7 \%$ respondent private job. 
Table \# 04

If your opinion what are the main reason of low literacy of girls in rural areas

\begin{tabular}{|l|c|c|c|c|}
\hline Reasons & Agree & Neutral & Disagree & Total \\
\hline \multirow{2}{*}{ Cow income } & 21 & 52 & 47 & 120 \\
\cline { 2 - 5 } & 17.5 & 43.3 & 39.2 & 100 \\
\hline \multirow{2}{*}{ Transport problem } & 40 & 41 & 39 & 120 \\
\cline { 2 - 5 } & 33.3 & 34.2 & 32.5 & 100 \\
\hline Family norms & 27 & 59 & 34 & 120 \\
\cline { 2 - 5 } & 22.5 & 49.2 & 28.3 & 100 \\
\hline Parents attitude & 17 & 63 & 40 & 120 \\
\hline Early age marriages & 14.2 & 52.5 & 33.3 & 100 \\
\cline { 2 - 5 } & 25 & 63 & 26.7 & 100 \\
\hline Personal interest & 20.8 & 52.5 & 36 & 120 \\
\cline { 2 - 5 } & 29 & 55 & 30.0 & 100 \\
\hline Absence of educational facilities & 24.2 & 45.8 & 30.0 & 120 \\
\cline { 2 - 5 } & 32 & 43.3 & 43 & 120 \\
\cline { 2 - 5 } & 26.7 & 49 & 35.8 & 100 \\
\hline Law of awareness & 28 & 40.8 & 0 & 120 \\
\cline { 2 - 5 } & 23.3 & 73 & 0 & 120 \\
\hline
\end{tabular}

Table 04 showed that that opinion what are the main reason of low literacy of girls in rural areas of the respondents, $43.3 \%$ respondent neutral followed by $39.2 \%$ respondents disagree and $17.5 \%$ respondents agree low income. $34.2 \%$ respondent neutral followed by $33.3 \%$ respondents agree and $32.5 \%$ respondents disagree coeducation. $49.2 \%$ respondent neutral followed by $28.3 \%$ respondents disagree and $22.5 \%$ respondents agree transport problem. $52.5 \%$ respondent neutral followed by $33.3 \%$ respondents disagree and $14.2 \%$ respondents agree family norms. $45.8 \%$ respondent neutral followed by $30.0 \%$ respondents disagree and $24.2 \%$ respondents agree early age marriages. $43.3 \%$ respondent neutral followed by $30.0 \%$ respondents disagree and $26.7 \%$ respondents agree personal interest. $40.8 \%$ respondent neutral followed by $35.8 \%$ respondents disagree and $23.3 \%$ respondents agree absence of education facilities. $60.8 \%$ respondent neutral and 39.2 respondents agree law of awareness.

Table \# 05

Is there any Government institute working for rural development in your locality

\begin{tabular}{|c|c|c|c|c|}
\hline Activity & To great extent & To some extent & Not at all & Total \\
\hline \multirow{2}{*}{ Educational development } & 27 & 56 & 37 & 120 \\
\hline & 22.5 & 46.7 & 30.8 & 100 \\
\hline \multirow[t]{2}{*}{ Skill development (technical education) } & 50 & 51 & 19 & 120 \\
\hline & 41.7 & 42.5 & 15.8 & 100 \\
\hline \multirow[t]{2}{*}{ Community physical infrastructure } & 61 & 38 & 21 & 120 \\
\hline & 50.8 & 31.7 & 17.5 & 100 \\
\hline \multirow[t]{2}{*}{ Health improvement } & 54 & 41 & 25 & 120 \\
\hline & 45.0 & 34.2 & 20.8 & 100 \\
\hline \multirow[t]{2}{*}{ Employment and income for rural people } & 68 & 30 & 22 & 120 \\
\hline & 56.7 & 25.0 & 18.3 & 100 \\
\hline \multirow[t]{2}{*}{ Development of farmer's associations } & 59 & 42 & 19 & 120 \\
\hline & 49.2 & 35.0 & 15.8 & 100 \\
\hline \multirow[t]{2}{*}{ Integration of women in rural development } & 58 & 45 & 17 & 120 \\
\hline & 48.3 & 37.5 & 14.2 & 100.0 \\
\hline \multirow[t]{2}{*}{ Capacity building } & 64 & 36 & 20 & 120 \\
\hline & 53.3 & 30.0 & 16.7 & 100 \\
\hline \multirow[t]{2}{*}{ People's participation } & 51 & 55 & 14 & 120 \\
\hline & 42.5 & 45.8 & 11.7 & 100 \\
\hline \multirow[t]{2}{*}{ Micro credit } & 31 & 58 & 31 & 120 \\
\hline & 25.8 & 48.3 & 25.8 & 100 \\
\hline
\end{tabular}

Table 05 depicted that that the Government institute working for rural development in your locality, of the respondents, $46.7 \%$ respondent to some extent followed by $30.8 \%$ respondents not at all and $22.5 \%$ respondents to great extent educational development. $42.5 \%$ respondent to some extent followed by $41.7 \%$ respondents to great 
extent and $15.8 \%$ respondent not at all skill development (technical education). $50.8 \%$ respondent to great extent followed by $31.7 \%$ respondents to great extent and $17.5 \%$ respondent not at all community physical infrastructure. $45.0 \%$ respondent to great extent followed by $34.2 \%$ respondents to some extent and $20.8 \%$ respondent not at all health improvement. $56.7 \%$ respondent to great extent followed by $25.0 \%$ respondents to some extent and $18.3 \%$ respondent not at all employment and income for rural people. $49.2 \%$ respondent to great extent followed by $35.0 \%$ respondents to some extent and 15.8\% respondents not at all development of farmers association. $48.3 \%$ respondent to great extent followed by $37.5 \%$ respondents to some extent and $14.2 \%$ respondents not at all integration of women in rural development. $53.3 \%$ respondent to great extent followed by $30.0 \%$ respondents to some extent and $16.7 \%$ respondents not at all capacity building. $45.8 \%$ respondent to some extent followed by $42.5 \%$ respondents to great extent and $11.7 \%$ respondents not at all people's participation. $48.3 \%$ respondent to some extent followed by $25.8 \%$ respondents to some extent and $25.8 \%$ respondents not at all micro credit.

\section{SUMMARY}

The word development does not mean a general process of social change. A process of development should have three major elements. Economic: The economic development of any society base on, which will manufacture the commodities and resources necessary for life. Social: The provision of a collection of social facilities and services (i.e., health facilities, educational facilities and welfare). These are non-productive needs of a society. Human: The improvement of the people themselves, both individually and communally, to understand their full potential, to utilize their skills and to play a positive part in shaping their society.Rural development usually refers to the procedure of improving the quality of life and financial well-being of group living in relatively areas. Rural development has usually centered on the development of natural wealth such as agriculture and forestry. Though, changes in international production networks and greater urbanization have changed the nature of rural areas. Increasingly tourism, recreation and place manufacturers, have replace resource origin and agriculture as main economic drivers. Education, private enterprise, physical infrastructure (roads and rail network, transportation), and social infrastructure all play significant role in development of rural areas. It also characterizes by its significance on locally created economic development strategies. In compare to urban region, which have many similarities, rural areas are highly distinctive from one another. For this cause there are a large no of rural progress approaches used internationally. The aim of the present study to find out the perception about factors affecting the rural development in Tehsil Gujranwala, District Gujranwala. At the first stage tehsil Jhang were selected from District Jhang, at the second stage three union councils (Haidery UC-96. Gulabwala UC-94 and Gohar Shah UC88) and two villages from UC-96 are MouzaPatwana and Pakywala, Villages of UC-94 are Shairwala and Qulkoraiyan and Villages of UC-88 are Shabirabad and Balo Shahabal were selected through simple random sampling technique. At the end a sample of 120 respondents were selected through convenient sampling technique and interviewed by using a well-designed interview schedule. Descriptive and inferential statistical technique were used for data analysis. To check the accuracy and suitability of research tool, 10 respondents were pretested. After making necessary correction in research tool, final data were manipulated. Finally data were analyzed through Statistical Package for Social Sciences. Descriptive and inferential statistics was applied. Following findings were found.

\subsection{Main Findings}

$>$ A major proportion i.e., 43.3\% respondent were belonged to 37-54 years age.

$>$ Age of respondents, $100 \%$ respondent of male.

$>$ More than two-third i.e. $61.7 \%$ respondents are farmer and belonged to agricultural families.

More than one-fourth $26.7 \%$ respondent have monthly family income 20001-25000 per month.

$>$ More than one-fourth $29.2 \%$ education of the respondents, have matriculated.

A large majority i.e. 79.2 percent of them were married.

$>$ More than one-third $35.0 \%$ caste of the respondents hasJutt.

$>$ A large majority i.e. $67.5 \%$ family types of the respondents have joint.

$>59.0 \%$ respondent to neutral that cultural constraints hurdle they face to acquire higher education.

$>44.2 \%$ respondent neutral parent illiteracy is hurdle they face to acquire higher education.

$>39.2 \%$ respondent disagree that personal interest is hurdle they face to acquire higher education.

$>42.5 \%$ respondent to neutral absence of education facilities are hurdle they face to acquire higher education.

$>43.3 \%$ respondent to neutral lack of awareness is hurdle they face to acquire higher education.

- $48.3 \%$ respondent to neutral teacher behavior is hurdle they face to acquire higher education.

$>45.8 \%$ respondent not at all high price, is hurdle in adoption of modern technology.

> $50.0 \%$ respondent to some extent poverty, is hurdle in adoption of modern technology.

$>36.7 \%$ respondent to some extent traditional value, are the hurdle in adoption of modern technology.

$>50.8 \%$ respondent to some extent lack of social networking is hurdle in adoption of modern technology.

$>51.7 \%$ respondent has yes long distance between markets and rural areas are affected the rural development. 
$>42.5 \%$ respondent not at all lack of health facilities, also affecting the rural development.

$>45.0 \%$ respondent to some extent feudal system, also affecting the rural development.

$>40.0 \%$ respondent to some extent high price (fuel, seeds, pesticides and etc.), also affecting the rural development.

$>52.5 \%$ respondent not at all poor infrastructure (roads, transportation, street, sewerage and etc.) also affecting the rural development.

$>49.2$ respondent Punjab Rural Support Program (PRSP), 26.7\% respondents National Rural Support Program (NRSP), 22.5\% respondent Agha Khan Rural Support Program (AKRSP) and only 1.7\% respondents others NGO working in the area.

\subsection{Suggestions}

$>$ We can develop the rural areas through the development of natural wealth such as agriculture.

$>$ We can develop the rural areas through the Provision of services (health facilities, educational facilities etc).

$>$ We can develop the rural areas through the Provision of social facilities (social relationship).

$>$ We can develop the rural areas through Physical infrastructure (roads and rail network, transportation etc).

$>$ We can develop the rural areas through Educational improvement.

$>$ We can develop the rural areas through establishment of Private enterprise.

$>$ To Improve education level through the reduction of Cultural constraints.

$>$ We can develop the rural areas through create awareness about education.

$>$ We can develop the rural areas through female participation in employment.

$>$ We can develop the rural areas through reduction of dependency ratio.

We can develop the rural areas through equal distribution of land.

$>$ We can develop the rural areas through reduction of Conflict.

$>$ We can develop the rural areas through availability of modern technologies.

$>$ We can develop the rural areas through capacity building of people.

$>$ We can develop the rural areas through development of farmer's associations.

$>$ We can develop the rural areas through Integration of women in rural areas.

\section{REFERENCES}

Abdul and Ahmed. 2007. Sustainable agriculture and eradication of rural poverty in Pakistan.Natural Resources Forum 31 (2007) 253-262

Ashraf, M. 1992. Factors affecting community participation in Rural Development in Tehsil ChakJhumra, Faisalabad District. M.Sc. Thesis University of Agriculture Faisalabad.

Asian Productivity Organization. 2004. Role of Local Communities and Institutions in Integrated Rural Development. Available at. www.apotokyo.org/publications/files/pjrep-icd-se-3-01.

Asim. 2009. Rural Development in Pakistan Rural Development Foundation Experiences in This Field. Available at.WWW.RDF.ORG.PK.

Atmis, E., I. Dasdemir, W. Lise and O.Yildiran. 2007. Factors Affecting Women's participation in Turkey. Ecological economics, 60(4):787-796.

Chaudhry, M.I. 1988. Sociology. Aziz Publisher Urdu Bazar Lahore

Chaudhry, S.M. 1984. Introduction to statistical theory Part-I. Published by IlamiKhutabKhana, Urdu Bazar Lahore, P. 3-4.

Chishti, Salim, and A. Lodhi.1988. Simultaneous Determination of Choice to Attend School, and the Demand for School Education: A Case Study of Karachi, Pakistan. Pakistan Journal of Applied Economics 7(2):101-108.

Ejaz A and K. Ali. 2008. Determinants of Schooling in Rural Areas of Pakistan. The Lahore Journal of Economics, Vol.8, No.2

Foddy, W. 1993. Constructing questions for interviews and questionnaires. Cambridge, UK: Cambridge University Press.

Francis, J.B. 1970. Educational Sociology. Prentice Hall INC, Englewood Cliffs, N.J. Carles Tuttle Company, Tokyo.

Goode and Hatt, 1952. Methods in social research. McGraw Hill Book Co. Inc. New York.

Imran, S., M. Shahnawaz and A. Muhammad. 2006. Rural Poverty in Pakistan Some Related Concepts, Issues and Empirical Analysis. Pakistan Economic and Social Review Volume, 44(2): 259-276

Khal, J.A. and J.A. Davis. 1955. A Comprehensive of Indexies of Socio-Economic Status. Amer. Social. Rev. Vol. 20.

Muhammad and Faheem.2007.Health Care Services and Government Spending in Pakistan.

Muhammad, I. and A. Nafees. 2009. Village Organizations Activities for Rural Development in North West Pakistan: A Case Study of Two Union Councils of District Shangla.

Muhammad, I., A. Mushtaq, B. Saima and M. Zafar. 2008. Factors Affecting the Mobilization of Rural Women 
ThroughSarhad Rural Support Program (Srsp) In District Peshawar.

Nachmias, C.F. and D.Nachmias. 1992. Resaerch Methods in the Social Sciences .Published by Edards Arnold, A division of Hodder \& Stoughton, London.

Nchuchuwe, and. Friday. 2012. The Challenges of Agriculture and Rural Development in Africa.Pakistan. Pakistan.26 (2): 27-35

Nie, Hull and Bent, 1968. Statistical Package for the Social Sciences (SPSS) Inc. 233 S. Wacker Drive Chicago, IL 60606

Popenoc, D. 1977. Sociology, Third Edition Prentice Hall, Inc. Englewood Cliffs, New Jersey, p. 568.

Shabbir, Ashfaq, A., and Amna.2005.Factors Affecting Skill Development and Job Opportunities for Young Females in Rural Faisalabad-Pakistan.Journal of agriculture \& social sciences1813-2235/2005/01-2-178$179 \mathrm{http}: / /$ www.ijabjass.org

Talat,Sarfraz, K., Qureshi and Hammad. 2004. Landlessness and Rural Poverty in Pakistan.

Wellman, B. 1998. The Community Question Re-evaluated. Pp. 81-107 in Power, Community and the City, edited by Michael Peter Smith. New Brunswick, NJ: Transaction.

Zulfiqar A, M. Khalid and A.Waqar. 1999. Rural Development in the 21st Century. The Pakistan Development Review,38(4):1177-1190. 